\title{
Prescription patterns of benzodiazepines in the Lebanese adult population: a cross-sectional study
}

This article was published in the following Dove Press journal:

Neuropsychiatric Disease and Treatment

6 September 2016

Number of times this article has been viewed

\author{
Wijdan H Ramadan' \\ Ghada M El Khoury' \\ Mary E Deeb ${ }^{2}$ \\ Marwan Sheikh-Taha' \\ 'School of Pharmacy, ${ }^{2}$ School of \\ Medicine, Lebanese American \\ University, Byblos, Lebanon
}

\begin{abstract}
This study assessed the profile of benzodiazepine (BDZ) users in Lebanon. Adult patients visiting the pharmacies with prescriptions of BDZs were included in the study. Seven hundred and eighty-six current BDZ users were included, of whom 54.2\% were females. Twentythree percent reported being alcohol consumers and were mostly males. The two most commonly used BDZs were alprazolam (34.6\%) and bromazepam (33.6\%). The indication for use was mainly anxiety (44.4\%), insomnia (22.5\%), and depression (15.9\%). The prescribing physicians were primarily psychiatrists $(43.2 \%)$, followed by general practitioners $(29.7 \%)$. Forty percent had been taking the drug for more than a year. Among those using BDZs for at least 1 month, $35.5 \%$ increased the dose with time. Thirty-three percent reported having experienced side effects. Eighteen patients (2.3\%) reported taking more than one BDZ concomitantly, while $18.3 \%$ were taking drugs that should not be prescribed along with BDZs. In conclusion, the use of BDZs is highest among females, especially for the treatment of anxiety. Moreover, continuous use of the drugs for more than a year as well as significant potential drug interactions was identified.
\end{abstract}

Keywords: benzodiazepines, prescribing patterns, controlled substances

\section{Introduction}

Nonmedical use of prescription medications is a growing global concern. ${ }^{1}$ The use of prescription drugs seems to be increasing at a faster rate than that of illicit substances. ${ }^{2}$ In Lebanon, $\sim 20 \%$ of the young adult population is taking psychoactive substances in nonmedical aspects that differ from the prescription recommendations. ${ }^{3,4}$ This practice puts the Lebanese population at increased risk for dangerous physical and psychological side effects. ${ }^{3}$ In addition to health implications, this practice has major economic consequences. While there is a lack of data on the economic impact of nonmedical use of prescription drugs in Lebanon, studies conducted in the US clearly highlighted its associated financial burden on society. ${ }^{5}$

Benzodiazepines (BDZs) are among the most widely and frequently used psychoactive substances in the world. They have an important role in clinical medicine and are used in numerous clinical conditions like anxiety and sleep disorders, alcohol withdrawal, the augmentation of antidepressants and antipsychotics, mania, muscle relaxation, seizures, as well as in many non-approved indications. ${ }^{6,7}$ Their clinical use, however, should be monitored closely due to their adverse effects and potential for misuse and abuse. Several adverse reactions have been associated with the use of BDZs including motor disturbances, cognitive decline, unwanted sedation, and reduced coordination. ${ }^{7}$

Across countries, studies have shown a relatively high prevalence of BDZ use in the general population with a somewhat different pattern of use ranging from as low as $6.2 \%$ 
in developed countries up to $36 \%$ in developing ones. ${ }^{8-21}$ In the US, a recent report revealed that a 12 -month prevalence of BDZ use as tranquilizers was $8.6 \%{ }^{22}$ A prevalence estimate of $9.2 \% \mathrm{BDZ}$ usage was reported from a combined population of six European countries. ${ }^{23}$ The prevalence of BDZ use in an elderly population of a Canadian province exceeds $10 \% .^{24}$

Most developed countries have routinely collected data on BDZs prescription and consumption; however, limited data exist on the rates and patterns of use in Lebanon. The main objective of this study is to assess the patterns of BDZs use, profile of users in Lebanon regarding their demographic characteristics, the clinical indication for use, duration of use, perceived side effects, and potential drugdrug interactions.

\section{Materials and methods}

This is an observational study that was conducted at 27 community pharmacies in Lebanon over a period of 2 years, from June 2012 till May 2014. The targeted population were ambulating Lebanese patients aged $\geq 18$ years, recruited in various community pharmacies across different regions of Lebanon. To ensure a representative sample of adults, the pharmacies were randomly selected across the six Lebanese governorates: North of Lebanon, Mount Lebanon, Beirut, South of Lebanon, Beqaa, and Nabatieh. Patients visiting the pharmacies with prescriptions of BDZs were asked if they were willing to participate in the study. Family members of patients who came to the pharmacies to get the BDZs were asked to provide the telephone number of the patients and about the possibility to call them. Phone interviews were done when patients consented to participate in the study. An interview questionnaire was used to collect the data. The study was approved by the LAU University Institutional Review Board, and a waiver of consent was obtained to fill out the questionnaire.

The questionnaire gathered data on sociodemographic characteristics including age, sex, place of residence, pregnancy, breastfeeding, and alcohol intake. Data on patterns of BDZ use included indication(s) for use, specialty of prescribing physician, duration of therapy, perceived side effects, concomitant medications used, and increase in BDZ dose with time.

Data were processed and analyzed through the application of the Statistical Package for Social Sciences (version 22; IBM Corporation, Armonk, NY, USA). The association of BDZ use by sociodemographic variables and indication, duration of use, and perceived side effects was assessed by applying the chi-square statistical test using a significance level of $5 \%$.

\section{Results \\ Sociodemographic characteristics}

Table 1 describes the sociodemographic characteristics of the 786 sampled BDZ current users, of whom $45.8 \%$ were males and $54.2 \%$ were females, and three were pregnant or breastfeeding. The proportion of BDZ users who agreed to participate in the study approached $86 \%$. Twenty-three percent reported being alcohol consumers, with a significant differential by age and sex of study participants. Males reported a significantly higher proportion of alcohol consumption $(33.5 \%)$ compared to female users (14.9\%), even after adjusting for age. There were $24(3.1 \%)$ and 21 individuals $(2.7 \%)$ who reported suffering from liver and renal diseases, respectively.

\section{BDZ use characteristics}

The two most commonly used BDZs were alprazolam (34.6\%) and bromazepam (33.6\%), followed by clonazepam (12.1\%) and lorazepam (10\%), and the least commonly used were diazepam (5.3\%), midazolam $(3 \%)$, and temazepam $(1.3 \%)$. There was a significant differential of type of medication used by sex specifically among the younger age group of users (20-50 years); the proportion of females using bromazepam was significantly higher (34.3\%) compared to males $(24.6 \%)$. Males were more frequent users of

Table I Distribution of sociodemographic characteristics of a sample BDZ current user

\begin{tabular}{ll}
\hline & Frequency \\
\cline { 2 - 2 } Sex & N (\%) \\
Male & \\
Female & $352(45.8)$ \\
Age (years) & $416(54.2)$ \\
$20-29$ & \\
$30-39$ & $48(6.3)$ \\
$40-49$ & $116(15.1)$ \\
$50-59$ & $184(24.0)$ \\
$60-69$ & $192(25.0)$ \\
$70+$ & $144(18.8)$ \\
Geographical distribution & $84(10.9)$ \\
Beirut & \\
Beirut suburbs & $172(22.4)$ \\
Byblos & $119(15.5)$ \\
Jounieh & $67(8.7)$ \\
Tripoli & $199(25.9)$ \\
Saida & $152(19.8)$ \\
Total & $59(7.7)$ \\
Proportion of alcohol consumption & $768(100.0)$ \\
Male & \\
Female & $(33.5)$ \\
BDZ consumers with comorbidities & $(14.9)$ \\
Renal disease & \\
Liver disease & $(2.7)$ \\
\hline Abreviation: BDZ & $(3.1)$ \\
\hline
\end{tabular}

Abbreviation: BDZ, benzodiazepine. 
diazepam (11.2\%) and clonazepam (19.0\%) compared to females ( $3 \%$ and $11.8 \%$, respectively) (Table 2 ).

The indication for BDZ use was mainly anxiety (44.4\%), insomnia (22.5\%), depression (15.9\%), epilepsy (5.7\%), minor surgery/procedures $(5.6 \%)$, schizophrenia (1.2\%), pain $(1.0 \%)$, muscle spasm $(0.4 \%)$, and multiple sclerosis $(0.3 \%)$. Reports of anxiety, insomnia, and depression were more frequently reported among females than males, while epilepsy, pain relief, and surgery seemed to be reported more frequently by males compared to females. When sex was stratified by age group, the sex differential was significant only among the younger age group, that is, those aged 20-50 years old (Table 3 ).

Table 4 shows that the distribution of type of BDZ medication differs significantly by reported indication for BDZ use. The most common drugs prescribed for anxiety, insomnia, depression, and pain relief were bromazepam and alprazolam; however, clonazepam was the drug of choice for epilepsy.

\section{Prescriber of the BDZ and duration of use}

The BDZ was usually prescribed by a medical doctor except for one case by a pharmacist for insomnia and three cases by a dentist for minor surgery. The prescribing physician was primarily a psychiatrist (43.2\%), a general practitioner $(29.7 \%)$, or a surgeon $(2.3 \%)$. There were nine cases where the BDZ was prescribed by a pediatrician, four for anxiety, four for insomnia, and one for pain relief.

The medical indication for prescribing BDZ varied significantly by the prescribing physician specialty. Psychiatrists prescribed BDZs mainly for anxiety and depression (65\%), followed by general practitioners (56\%), cardiologists (53\%), and other specialists (49\%).

Approximately $15 \%$ of the patients were taking BDZ on an "as-needed" basis, and $40 \%$ had been taking the drug for more than a year. The duration of BDZ use for $>1$ year did differ significantly by the specialty of the prescribing physician; it was reported as $52 \%$ among cardiologists and $43 \%$ by psychiatrists compared to $34 \%$ by general practitioners and other specialists. Table 5 shows the distribution of duration of therapy by physician specialty.

\section{Interval for BDZ dosage increase and perceived side effects}

All the patients who had used the BDZ medication for at least 1 month were asked to report on the timing of the increase in the BDZ dose and its side effect. The proportion of the sample who had not started their BDZ medication yet was $6.1 \%$. Among those who had used their medication for at least

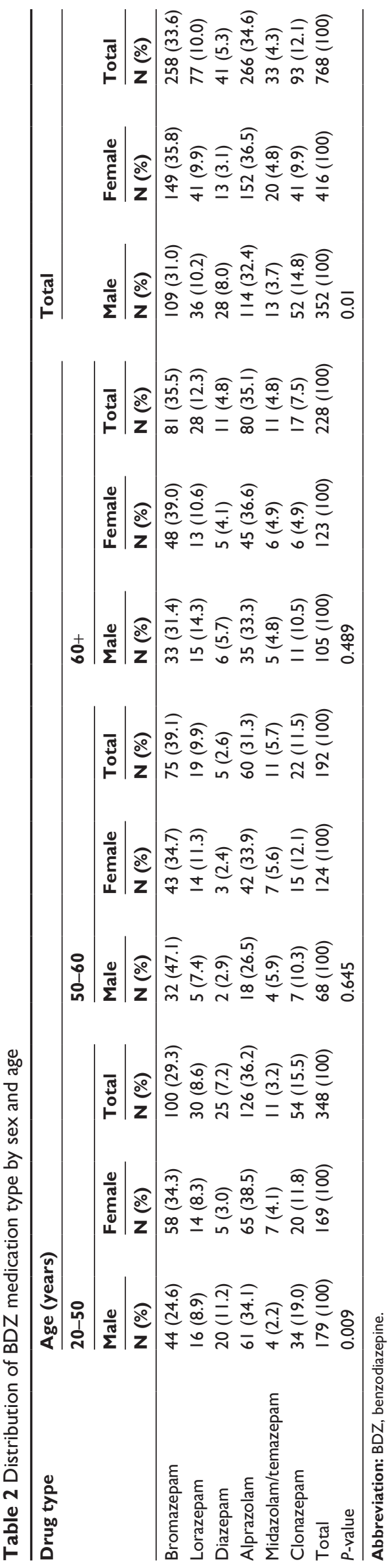




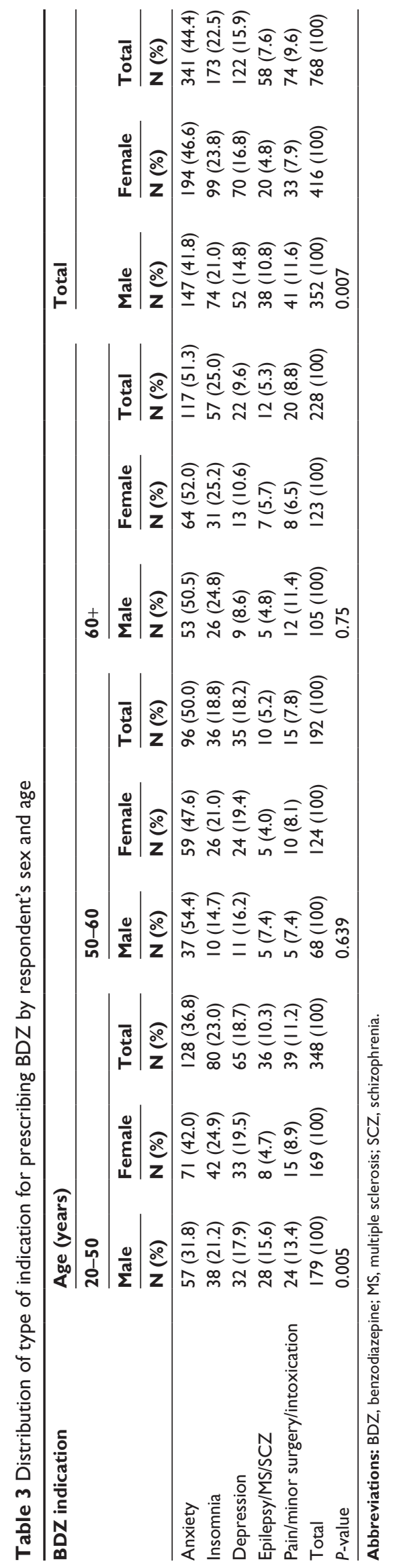

1 month, $64.5 \%$ did not increase the dose, while $7.6 \%$ did after 1 month, $3.6 \%$ after 2 months, $8.9 \%$ after 3 months, and $9.4 \%$ after 6 months. There was no differential in the reported BDZ dosage increase by participant sex controlling for BDZ user age interval in years. Only $1.2 \%$ of all BDZ users reported having to take a higher dose than recommended by the manufacturers.

Thirty-three percent (237 cases) of the surveyed users reported having experienced side effects due to the intake of BDZ. The reported side effects were restlessness (38\%), display of aggressive behavior (15.6\%), headache (11.4\%), delusions $(10.5 \%)$, inappropriate behavior $(10.1 \%)$, nightmares $(9.7 \%)$, and stomach upset $(4.6 \%)$. The reported perceived side effects did not vary significantly by sex and age of the study participants. However, there was a significant variation in prevalence of side effects by type of medication prescribed. Perception of side effects was reported most frequently among those taking bromazepam and the least among those on diazepam.

Perception of reported side effects was significantly associated with the medication duration of use being more frequent among those who use it on an as-needed basis and among those who have been using it for $>2$ months.

\section{Duplication of BDZ drug therapy}

In order to check for possible BDZ drug duplication therapy, the names of the different BDZs were cross-checked and analyzed. The duplication of therapy was noted among 18 patients $(2.3 \%)$ only.

\section{Use of other medications}

Patients were asked whether they were taking other mediation with BDZ, and $56.1 \%$ reported taking other medications. Among those who reported taking other medication, 18.3\% of the cases were taking drugs that should not be prescribed along with BDZs. The type of potential drug-drug interaction was analyzed, and the results are shown in Table 6.

\section{Discussion}

The discovery of BDZs in the late 50s was met with a lot of excitement by physicians leading to an alarming rise of their use around the world. ${ }^{1}$ This study assessed the profile of BDZ users in Lebanon. Among Lebanese BDZ users, there was a slight preponderance of females, a finding consistent with previously published trials. ${ }^{8,15,16,20,25}$ Facts that might explain this finding are the higher prevalence of anxiety among females, as well as the higher life expectancy and higher compliance described in females..$^{13,26}$ 
Table 4 Distribution of type of BDZ medication by indication of use

\begin{tabular}{|c|c|c|c|c|c|c|c|}
\hline \multirow[t]{3}{*}{ BDZ type } & \multicolumn{5}{|c|}{ BDZ drug indication } & \multirow{3}{*}{$\begin{array}{l}\text { Total } \\
\text { N (\%) }\end{array}$} & \multirow[t]{3}{*}{$P$-value } \\
\hline & Anxiety & Insomnia & Depression & Epilepsy/MS/SCZ & Pain/intoxication & & \\
\hline & $\mathbf{N}(\%)$ & $\mathbf{N}(\%)$ & $\mathbf{N}(\%)$ & $\mathbf{N}(\%)$ & $\mathbf{N}(\%)$ & & \\
\hline Bromazepam & 125 & $54(31.2)$ & $45(36.9)$ & $9(15.5)$ & $25(33.8)$ & $258(33.6)$ & 0.000 \\
\hline Lorazepam & $29(8.5)$ & $24(I 3.9)$ & $13(10.7)$ & $5(8.6)$ & $6(8.1)$ & $77(10.0)$ & \\
\hline Diazepam & $14(4.1)$ & $4(2.3)$ & $6(4.9)$ & $7(12.1)$ & $10(13.5)$ & $4 \mid(5.3)$ & \\
\hline Alprazolam & $140(4||)$. & $54(3 \mid .2)$ & $42(34.4)$ & $12(20.7)$ & I8 (24.3) & $266(34.6)$ & \\
\hline Midazolam/temazepam & $4(1.2)$ & $23(13.3)$ & $2(1.6)$ & $0(0.0)$ & $4(5.4)$ & $33(4.3)$ & \\
\hline Clonazepam & $29(8.5)$ & $14(8.1)$ & $14(11.5)$ & $25(43.1)$ & II (I4.9) & $93(12.1)$ & \\
\hline Total & $34 I(100)$ & $173(100)$ & $122(100)$ & $58(100)$ & $74(100)$ & $768(100)$ & \\
\hline
\end{tabular}

Abbreviations: BDZ, benzodiazepine; MS, multiple sclerosis; SCZ, schizophrenia.

Most BDZs are considered to have similar efficacy; therefore, selection is based on pharmacokinetic considerations and the US Food and Drug Administration (FDA)labeled indication. The two most common types of BDZs used were alprazolam and bromazepam, both of which are intermediate acting with a relatively rapid onset of action as compared to other BDZs. ${ }^{27}$ Bromazepam and alprazolam were also found to be mostly used in Pakistan. ${ }^{16,18}$ Clonazepam was mainly used for seizure disorders as it is one of the few BDZs approved by the FDA for this indication. One of the least-used agents was diazepam characterized by its much longer half-life and increased tolerance. ${ }^{27}$

According to the World Health Organization, anxiety is the most prevalent mental disorder. ${ }^{28}$ In addition, $~ 30 \%$ of a variety of adult samples drawn from different countries report having insomnia. ${ }^{29}$ Among the Lebanese BDZ users, 44.4\% were taking the $\mathrm{BDZ}$ for anxiety and $22.5 \%$ for insomnia followed by $16 \%$ for depression. Studies suggest that BDZ can be an effective option for patients with anxiety with minimal roles for other indications as depression, muscle relaxation, and schizophrenia. Furthermore, the better safety profile of the newer non-BDZ hypnotics (ie, zolpidem, zaleplon, eszopiclone, and ramelteon) makes them better first-line pharmacological choices for the management of insomnia. Despite that, numerous studies have shown that BDZs are overprescribed for extended periods in many countries. ${ }^{30-32}$ The findings of this study indicated that a proportion of patients were inappropriately using BDZs for indications like pain management and continued use after minor surgeries.

A little less than half of the patients reported continuous use of BDZs for more than a year. Among prescribers, cardiologists and psychiatrists tend to prescribe BDZs for a longer period of time which might be explained by the chronic diseases they usually treat. Doses used were increased by $\sim 35 \%$ after the first month that could be due to tolerance to the agents but remained therapeutic. BDZs are associated with troublesome sedation and cognitive impairment as well as tolerance and dependence with prolonged use. ${ }^{33}$ Recommendations for the duration of treatment with BDZ especially in elderly are usually no more than 2-4 weeks of continuous use. ${ }^{34}$ In resistant or critical severe cases, BDZs should not be used for $>8-12$ weeks,

Table 5 Distribution of duration of therapy by physician specialty

\begin{tabular}{|c|c|c|c|c|c|}
\hline \multirow[t]{2}{*}{ Duration of therapy } & \multicolumn{4}{|c|}{ Physician specialty } & \multirow{2}{*}{$\begin{array}{l}\text { Total } \\
\text { Frequency (\%) }\end{array}$} \\
\hline & $\begin{array}{l}\text { Psychiatryl } \\
\text { neurology } \\
\text { Frequency (\%) }\end{array}$ & $\begin{array}{l}\text { Cardiology } \\
\text { Frequency (\%) }\end{array}$ & $\begin{array}{l}\text { General } \\
\text { practice } \\
\text { Frequency (\%) }\end{array}$ & $\begin{array}{l}\text { Other specialty } \\
\text { Frequency (\%) }\end{array}$ & \\
\hline As needed & $\begin{array}{l}52 \\
(I 5.7)\end{array}$ & $\begin{array}{l}14 \\
(13.0)\end{array}$ & $\begin{array}{l}37 \\
(16.2)\end{array}$ & $\begin{array}{l}15 \\
(15.0)\end{array}$ & $\begin{array}{l}118 \\
(15.4)\end{array}$ \\
\hline 2 weeks -2 months & $\begin{array}{l}33 \\
(9.9)\end{array}$ & $\begin{array}{l}8 \\
(7.4)\end{array}$ & $\begin{array}{l}38 \\
(16.7)\end{array}$ & $\begin{array}{l}14 \\
(14.0)\end{array}$ & $\begin{array}{l}93 \\
(12.1)\end{array}$ \\
\hline $2-6$ months & $\begin{array}{l}50 \\
(15.1)\end{array}$ & $\begin{array}{l}\text { II } \\
(10.2)\end{array}$ & $\begin{array}{l}30 \\
(13.2)\end{array}$ & $\begin{array}{l}20 \\
(20.0)\end{array}$ & $\begin{array}{l}\text { III } \\
(14.5)\end{array}$ \\
\hline 6-12 months & $\begin{array}{l}54 \\
(16.3)\end{array}$ & $\begin{array}{l}19 \\
(17.6)\end{array}$ & $\begin{array}{l}47 \\
(20.6)\end{array}$ & $\begin{array}{l}17 \\
(17.0)\end{array}$ & $\begin{array}{l}137 \\
(17.8)\end{array}$ \\
\hline$>$ I year & $\begin{array}{l}143 \\
(43.1)\end{array}$ & $\begin{array}{l}56 \\
(51.9)\end{array}$ & $\begin{array}{l}76 \\
(33.3)\end{array}$ & $\begin{array}{l}34 \\
(34.0)\end{array}$ & $\begin{array}{l}309 \\
(40.2)\end{array}$ \\
\hline Total & $\begin{array}{l}332 \\
(100.0)\end{array}$ & $\begin{array}{l}108 \\
(100.0)\end{array}$ & $\begin{array}{l}228 \\
(100.0)\end{array}$ & $\begin{array}{l}100 \\
(100.0)\end{array}$ & $\begin{array}{l}768 \\
(100.0)\end{array}$ \\
\hline
\end{tabular}


Table 6 Distribution of BDZ drug users who reported taking other medication by type of expected drug interaction

\begin{tabular}{|c|c|c|c|}
\hline Type of drug interaction & Frequency & Percentage & Interacting drugs \\
\hline $\begin{array}{l}\text { Inhibition of BDZ metabolism/ } \\
\text { increase serum level or effect }\end{array}$ & 20 & 30 & $\begin{array}{l}\text { Antifungals, SSRIs, oral } \\
\text { contraceptives }\end{array}$ \\
\hline Additive CNS depression & 45 & 66 & $\begin{array}{l}\text { Hypnotics, antipsychotics, } \\
\text { TCAs, antiepileptics, opiates }\end{array}$ \\
\hline $\begin{array}{l}\text { Induction of BDZ metabolism/ } \\
\text { decrease serum level or effect }\end{array}$ & 3 & 4 & Carbamazepine \\
\hline Total & 68 & 100 & \\
\hline
\end{tabular}

Abbreviations: BDZ, benzodiazepine; SSRIs, selective serotonin reuptake inhibitors; CNS, central nervous system; TCAs, tricyclic antidepressants.

as tolerance and physical and psychological dependence can occur. The findings of this study highlight the scale of the need for interventions to reinforce the adherence to guidelines by having clinicians use the lowest therapeutic doses for the briefest duration of time.

The study participants were prescribed BZDs by qualified health care providers except for cases where BDZs were prescribed by community pharmacists not entitled to dispense controlled substances. Nine adults were prescribed BDZs by pediatricians which raises the question about the justification of those prescriptions. Previously published evidence showed the easy access to prescription medications in Lebanon and documented a lack of awareness on the dangers of prescription misuse. The role of the Lebanese pharmacists in dispensing prescription drugs without medical prescriptions has been identified as a major contributor, while the role of the Lebanese government in controlling the drug supply system was described as insufficient.,

It was found that $23 \%$ of BDZ users reported being alcohol consumers and were more likely to be males. The higher percentage of males being alcohol consumers as compared to females is consistent with older studies as females may carry a lower genetic risk for alcohol use disorders while males have fewer perceived social sanctions for drinking. ${ }^{35,36}$ Alcohol has a documented potentiation effect on gammaaminobutyric acid receptors. In addition to alcohol intake, a significant proportion of the study participants reported taking other medications that interacted significantly with BDZ either by affecting its metabolism (antifungals, oral contraceptives, selective serotonin reuptake inhibitors) or by potentiating its central nervous system depression effects. These important drug-drug interactions are associated with drug-induced death, drug overdoses, and traffic accidents or fatalities and require adequate patient education and awareness by prescribers and pharmacists. ${ }^{28}$

One of the limitations of this study is its observational nature. Not all Lebanese pharmacies were included in the sample; however, the big number of patients recruited from different geographical areas as well as the long duration of the study diluted this limitation and made the sample representative. Additionally, patients' self-reporting of side effects to BDZ could have been subjective and confounded by patient's disease states and/or concomitant medications. Also, it would be possible that more patients were taking higher doses than recommended by the manufacturer than being reported and were reluctant to admit the misuse of their medications.

Despite the mentioned limitations, the major strength of this study resides in the fact that it was the first one to report on BDZ use across a large number of individuals from across the country.

\section{Conclusion}

Understanding the patterns of BDZ use in the Lebanese community is an essential first step toward the implementation of interventions to reduce its misuse and abuse. To our knowledge, the present study is the first to report patterns of BDZ in the Lebanese adult ambulatory population. Results showed that the use of this class of medication is highest among females especially for the treatment of anxiety. Moreover, continuous use of the drugs for more than a year as well as significant potential drug interactions was identified. A collaborative effort of governmental bodies and health care providers is recommended to educate, regulate, and promote the appropriate and safe use of BDZ.

\section{Disclosure}

The authors report no conflicts of interest in this work.

\section{References}

1. Kuehn BM. Prescription drug abuse rises globally. JAMA. 2007; 297(12):1306.

2. Goldsworthy RC, Schwartz NC, Mayhorn CB. Beyond abuse and exposure: framing the impact of prescription-medication sharing. Am J Public Health. 2008;98(6):1115-1121.

3. Ghandour LA, El Sayed DS, Martins SS. Prevalence and patterns of commonly abused psychoactive prescription drugs in a sample of university students from Lebanon: an opportunity for cross-cultural comparisons. Drug Alcohol Depend. 2012;121(1-2):110-117. 
4. Ghandour LA, El Sayed DS, Martins SS. Alcohol and illegal drug use behaviors and prescription opioids use: how do nonmedical and medical users compare, and does motive to use really matter? Eur Addict Res. 2013;19(4):202-210.

5. Birnbaum HG, White AG, Reynolds JL, et al. Estimated costs of prescription opioid analgesic abuse in the United States in 2001: a societal perspective. Clin J Pain. 2006;22(8):667-676.

6. Rickels K, Lucki I, Schweizer E, García-España F, Case WG. Psychomotor performance of long-term benzodiazepine users before, during, and after benzodiazepine discontinuation. J Clin Psychopharmacol. 1999;19(2):107-113

7. Salzman C. Issues and controversies regarding benzodiazepine use. NIDA Res Monogr. 1993;131:68-88.

8. Magrini N, Vaccheri A, Parma E, et al. Use of benzodiazepines in the Italian general population: prevalence, pattern of use and risk factors for use. Eur J Clin Pharmacol. 1996;50(1-2):19-25.

9. Naja WJ, Pelissolo A, Haddad RS, Baddoura R, Baddoura C. A general population survey on patterns of benzodiazepine use and dependence in Lebanon. Acta Psychiatr Scand. 2000;102(6):429-431.

10. Dunbar GC, Perera MH, Jenner FA. Patterns of benzodiazepine use in Great Britain as measured by a general population survey. $\mathrm{Br} J$ Psychiatry. 1989;155:836-841.

11. Appelberg K, Romanov K, Honkasalo ML, Koskenvuo M. The use of tranquilizers, hypnotics and analgesics among 18,592 Finnish adults: associations with recent interpersonal conflicts at work or with a spouse. J Clin Epidemiol. 1993;46(11):1315-1322.

12. Olfson M, Pincus HA. Use of benzodiazepines in the community. Arch Intern Med. 1994;154(11):1235-1240.

13. Swartz M, Landerman R, George LK, Melville ML, Blazer D, Smith K. Benzodiazepine anti-anxiety agents: prevalence and correlates of use in a Southern community. Am J Public Health. 1991;81(5):592-596.

14. van der Waals F, Mohrs J, Foets M. Sex differences among recipients of benzodiazepines in Dutch general practice. BMJ. 1993;307(6900): 363-366.

15. Pariente P, Lepine JP, Lellouch J. Self-reported psychotropic drug use and associated factors in a French community sample. Psychol Med. 1992;22(1):181-190.

16. Patel MJ, Ahmer S, Khan F, Qureshi AW, Shehzad MF, Muzaffar S. Benzodiazepine use in medical out-patient clinics: a study from a developing country. J Pak Med Assoc. 2013;63(6):717-720.

17. Kapczinski F, Amaral OB, Madruga M, Quevedo J, Busnello JV, de Lima MS. Use and misuse of benzodiazepines in Brazil: a review. Subst Use Misuse. 2001;36(8):1053-1069.

18. Ahmer S, Salamat S, Khan RA, et al. Pattern of benzodiazepine use in psychiatric outpatients in Pakistan: a cross-sectional survey. Clin Pract Epidemiol Ment Health. 2009;5:9.

19. Zandstra SM, Furer JW, van de Lisdonk EH, et al. Different study criteria affect the prevalence of benzodiazepine use. Soc Psychiatry Psychiatr Epidemiol. 2002;37(3):139-144.

20. Bonsack C, Camus D, Kaufmann N, et al. Prevalence of substance use in a Swiss psychiatric hospital: interview reports and urine screening. Addict Behav. 2006;31(7):1252-1258.
21. Lagnaoui R, Depont F, Fourrier A, et al. Patterns and correlates of benzodiazepine use in the French general population. Eur J Clin Pharmacol. 2004;60(7):523-529.

22. Substance Abuse and Mental Health Services Administration. Results from the 2009 national survey on drug use and health: volume I. Summary of national findings (Office of Applied Studies, NSDUH series H-38A, HHS publication no. SMA 10-4856 findings). Rockville, MD: Substance Abuse and Mental Health Services Administration; 2010.

23. Demyttenaere K, Bonnewyn A, Bruffaerts R, et al. Clinical factors influencing the prescription of antidepressants and benzodiazepines: results from the European study of the epidemiology of mental disorders (ESEMeD). J Affect Disord. 2008;110(1-2):84-93.

24. Alessi-Severini S, Dahl M, Schultz J, Metge C, Raymond C. Prescribing of psychotropic medications to the elderly population of a Canadian province: a retrospective study using administrative databases. PeerJ. 2013;1:e168.

25. Iqbal SP, Ahmer S, Farooq S, et al. Benzodiazepine use among adults residing in the urban settlements of Karachi, Pakistan: a cross sectional study. Subst Abuse Treat Prev Policy. 2011;6:19.

26. Voyer P, Cohen D, Lauzon S, Collin J. Factors associated with psychotropic drug use among community-dwelling older persons: a review of empirical studies. BMC Nurs. 2004;3(1):3.

27. Bailey L, Ward M, Musa MN. Clinical pharmacokinetics of benzodiazepines. J Clin Pharmacol. 1994;34(8):804-811.

28. Demyttenaere K, Bruffaerts R, Posada-Villa J, et al; WHO World Mental Health Survey Consortium. Prevalence, severity, and unmet need for treatment of mental disorders in the World Health Organization World Mental Health Surveys. JAMA. 2004;291(21):2581-2590.

29. Ancoli-Israel S, Roth T. Characteristics of insomnia in the United States: results of the 1991 National Sleep Foundation Survey. I. Sleep. 1999;22 Suppl 2:S347-S353.

30. Cook JM, Marshall R, Masci C, Coyne JC. Physicians' perspectives on prescribing benzodiazepines for older adults: a qualitative study. $J$ Gen Intern Med. 2007;22(3):303-307.

31. Mant A, Duncan-Jones P, Saltman D, et al. Development of long term use of psychotropic drugs by general practice patients. $\mathrm{Br} \mathrm{Med} J$ (Clin Res Ed). 1988;296(6617):251-254.

32. Siriwardena AN, Qureshi MZ, Dyas JV, Middleton H, Orner R. Magic bullets for insomnia? Patients' use and experiences of newer ( $\mathrm{Z}$ drugs) versus older (benzodiazepine) hypnotics for sleep problems in primary care. Br J Gen Pract. 2008;58(551):417-422.

33. Dell'osso B, Lader M. Do benzodiazepines still deserve a major role in the treatment of psychiatric disorders? A critical reappraisal. Eur Psychiatry. 2013;28(1):7-20.

34. American Psychiatric Association. Benzodiazepine Dependence, Toxicity, and Abuse: Task Force Report. Arlington, VA: American Psychiatric Publishing; 1990.

35. Nolen-Hoeksema S. Gender differences in risk factors and consequences for alcohol use and problems. Clin Psychol Rev. 2004;24(8):981-1010.

36. Nolen-Hoeksema S, Hilt L. Possible contributors to the gender differences in alcohol use and problems. J Gen Psychol. 2006;133(4):357-374.
Neuropsychiatric Disease and Treatment

\section{Publish your work in this journal}

Neuropsychiatric Disease and Treatment is an international, peerreviewed journal of clinical therapeutics and pharmacology focusing on concise rapid reporting of clinical or pre-clinical studies on a range of neuropsychiatric and neurological disorders. This journa is indexed on PubMed Central, the 'PsycINFO' database and CAS,

\section{Dovepress}

and is the official journal of The International Neuropsychiatric Association (INA). The manuscript management system is completely online and includes a very quick and fair peer-review system, which is all easy to use. Visit http://www.dovepress.com/testimonials.php to read real quotes from published authors. 